\title{
IMPACTO DE LOS INCENDIOS FORESTALES EN COMUNIDADES VEGETALES SUB-MEDITERRÁNEAS: EVALUACIÓN MULTITEMPORAL DE LA DIVERSIDAD DEL PAISAJE UTILIZANDO IMÁGENES LANDSAT TM
}

\author{
F. PÉREZ-CABELLO(1), P. IBARRA BENLLOCH(1) \\ J. DE LA RIVA FERNÁNDEZ(1), M. T. ECHEVERRÍA ARNEDO(1) \\ R. MONTORIO LLOVERÍA ${ }^{(1)}$, A. GARCÍA-MARTÍN(1) \\ (1) Departamento de Geografía y O.T. (Universidad de Zaragoza) \\ C/ Pedro Cerbuna, 12, Zaragoza 50009 \\ Correo electrónico de contacto: fcabello@unizar.es
}

\begin{abstract}
RESUMEN. Se analiza el impacto y la evolución de la estructura del paisaje en un incendio del Prepirineo aragonés utilizando 6 imágenes Landsat 5 TM, identificando relaciones entre valores de heterogeneidad espacial y comunidades vegetales. Se extraen los NDVI (Normalized Difference Vegetation Index), se calcula el índice de Shannon y se cartografía para cada año. Se definen tres componentes representativos de los valores de diversidad (preincendio, a corto plazo y a medio plazo). Se concluye que a nivel de comunidad vegetal el incendio ha supuesto un incremento de la diversidad interna en algunas comunidades. No obstante, a medio plazo y a escala global el fuego provoca la homogeneización del paisaje, tal y como describen otros autores utilizando fuentes de información similar.
\end{abstract}

ABSTRACT. The impact and the evolution of the structure of the landscape in a forest fire of the PrePyrenees of Aragón using a set of 6 Landsat 5 TM images is analyzed, identifying the relationships between the space heterogeneity values and the vegetation types. NDVI values are extracted, obtaining the Shannon Index and performing its yearly cartography. Three representative components of the values of diversity are defined (prefire, short- and mid-term). It is concluded that at plant-community level the fire has generated an increase of the internal diversity. Nevertheless, in the mid-term and at a global scale the fire produces the landscape homogenization, as different authors describe using sources of similar information.

Palabras clave: incendios forestales, paisaje, montaña mediterránea, NDVI.

Key-Words: forest fires, landscape, Mediterranean mountain, NDVI. 


\section{Introducción}

En la cuenca mediterránea el fuego constituye uno de los factores ambientales de mayor importancia en la configuración de los paisajes forestales, tanto por haber sido utilizado secularmente como herramienta de gestión, como por la frecuencia de su incidencia por motivos naturales. En este sentido, el análisis de las consecuencias del fuego sobre las estructuras de paisaje presenta un notable interés tanto para comprender e interpretar la génesis de la estructura del paisaje de los ecosistemas actuales, como para responder adecuadamente con medidas correctoras a los efectos negativos de las zonas incendiadas.

En relación con este último extremo, el incremento de la frecuencia de incendios en las últimas décadas se yergue como uno de los principales factores que explican el desarrollo de paisajes altamente combustibles por su continuidad y uniformidad espacial. Otros factores de carácter antrópico como el proceso de abandono de cultivos en áreas de agricultura marginal, la reducción de los aprovechamientos tradicionales del monte, las repoblaciones forestales mono-específicas, operan en el mismo sentido, explicando el significativo incremento de los grandes incendios y sus nefastas consecuencias ambientales.

El efecto del fuego más inmediato y de mayor envergadura ecológico-paisajística se manifiesta en el calcinamiento de la vegetación, consistente tanto en la quema directa como en la deshidratación de los tejidos vegetales debido a las elevadas temperaturas del fuego (Rodríguez, 1996). En cuanto a la recuperación posterior, numerosos autores (Papió, 1994; Trabaud, 1998; Ferran y Vallejo, 1998), describen el proceso de regeneración en los primeros momentos tras el fuego como una función logarítmica debido a la rapidez con que se colonizan los suelos desnudos. En cualquier caso, los ritmos de crecimiento vienen controlados por las características del fuego, el grado de destrucción del contenido biológico - supervivencia de la biomasa subterránea y de los bancos de semillas-, los antecedentes fisonómicos, taxonómicos y de uso de los ecosistemas afectados, de la influencia de ciertos condicionantes ambientales posteriores al fuego, amén, evidentemente, de las posibles estrategias de recuperación diseñadas por el hombre.

Las consecuencias del fuego sobre la diversidad son muy variadas en función, entre otros factores, de la escala con que se analice, del sistema de medición o de las fuentes de información que se empleen. En términos globales, algunos autores apuntan a que las fases inmediatas que siguen al fuego se caracterizan por un incremento de la uniformidad como consecuencia de la destrucción de la vegetación por la combustión (Chuvieco, 1996). Lloret et al. (2002) observan un incremento de la densidad de parches y un decremento del tamaño de los mismos en zonas quemadas como consecuencia de que el fuego provoca diferentes etapas de sucesión vegetal que coexisten en una misma zona.

La espacialización y medición de la eco-diversidad (Wickham y Norton, 1994) se ha mejorado en los últimos años gracias al desarrollo de las tecnologías de la información geográfica -teledetección y sistemas de información geográfica (Burrough y MacDonell, 1998)-, así como a la consolidación del marco teórico y metodológico relativo a las influencias operativas de la ecodiversidad sobre la diversidad de especies (Legendre y Legendre, 1998; Mazerolle y Villard, 1999; Guisan y Zimmernman, 2000). 
Para la medición de la diversidad de paisajes, hábitats, ecosistemas o unidades ambientales se han propuesto una multiplicidad de índices (Turner y Gardner 1991), la mayoría de ellos correlacionados (Cain et al., 1997; Ritters et al., 1995), pero que suelen tener en cuenta, por norma general, el número de clases diferentes y la equitatividad de su reparto. El Índice de Shannon (H') es el más comúnmente utilizado para caracterizar la diversidad de categorías en un espacio. En este contexto, la obtención de valores espacialmente distribuidos de diversas características de la ecodiversidad se convierte en elemento esencial en el estudio de las causas directoras del desigual reparto del número de especies animales y de flora sobre el territorio y, por ende, en elemento necesario para la mejora de las políticas e instrumentos de planificación.

Los productos de teledetección espacial proporcionan una perspectiva muy adecuada para valorar los efectos del fuego sobre el paisaje a escala regional (Chuvieco, 1999). La conexión más importante entre la Ecología del Paisaje y la teledetección espacial reside en la importancia de la vegetación en la determinación de la estructura del paisaje y en el enorme potencial de la teledetección para analizar las características de la cubierta vegetal (composición, distribución espacial...).

Entre los índices empleados para analizar la respuesta vegetal frente al fuego destaca el NDVI (Normalized Difference Vegetation Index). Este neocanal, basado en las diferencias entre las bandas del rojo (r) 0,63 a $0,69 \mu \mathrm{m}$ y del infrarrojo cercano (irc) 0,78 a $0,90 \mu \mathrm{m}$, (Rouse et al., 1974), presenta un alto grado de correlación con algunas propiedades bióticas -biomasa vegetal, fracción de cobertura vegetal, índice de superficie foliar (Leaf Area Index) - (Elmore et al., 2000), independientemente de las especies vegetales que integren la comunidad (Gamon et al., 1995; Gilabert et al., 1997) por lo que ha sido tradicionalmente utilizado en el estudio de la cubierta vegetal. En este sentido son numerosos los trabajos que utilizan el NDVI como indicador de la tasa de recuperación de las comunidades vegetales después del fuego (e.g., Meliá et al., 1997; Viedma et al., 1997; Díaz Delgado et al., 1998; Díaz Delgado y Pons, 1999, 2001; Miller y Yool, 2002; Martínez et al., 2001; Riaño et al., 2002).

En ocasiones, el índice, además de utilizarse para realizar perfiles multitemporales sobre el proceso de regeneración, se emplea para explicar las discontinuidades espaciales de los valores de regeneración con variables de tipo físico (Díaz-Delgado y Pons, 1999). Sin embargo, conviene señalar que el análisis de la cubierta vegetal mediante el NDVI sólo explora la regeneración en términos de las propiedades bióticas con las que se correlaciona, no siendo operativo en el análisis de la componente fisonómica o florística del proceso de regeneración. Esta vertiente puede ser abordada mediante clasificación multitemporal o con la incorporación de datos de inventarios florísticos, pese a la complejidad de correlacionar información de campo con registros de satélite (Salvador, 1999); razón por la cual son escasos los trabajos en esta línea cuando el análisis se realiza en clave ecológica (Elmore et al., 2000). En este contexto, el objetivo del presente trabajo es analizar la evolución de la estructura del paisaje en una zona incendiada, en relación con valores de diversidad, utilizando imágenes procedentes del satélite Landsat-5, sensor Thematic Mapper. 


\section{Material y métodos}

\section{1. Área de estudio}

El incendio forestal analizado se localiza en el Prepirineo aragonés, concretamente, en la cabecera del Barranco de Nofuentes, al norte de la Sierra de Santo Domingo (municipio de Las Peñas de Riglos, Huesca), en el monte de repoblación HU 1045 denominado "Pardina Nofuentes" (Figura 1). El siniestro tuvo como origen un rayo y fue detectado el 21 de agosto de 1990, extinguiéndose al día siguiente tras calcinarse un total de 400 ha. Las comunidades vegetales afectadas fueron muy diversas como consecuencia de la variedad litológica, del dispositivo morfo-topográfico estribaciones septentrionales de las Sierra Exteriores, del peculiar contexto biogeográfico en el que se inscribe -zona de contacto entre las regiones Mediterránea y Eurosiberiana (precipitación media anual de $850 \mathrm{~mm}$; temperatura media de $10,5^{\circ} \mathrm{C}$ ) - y del historial de incendios y repoblaciones forestales al que se ha visto sujeto este sector del Prepirineo aragonés.

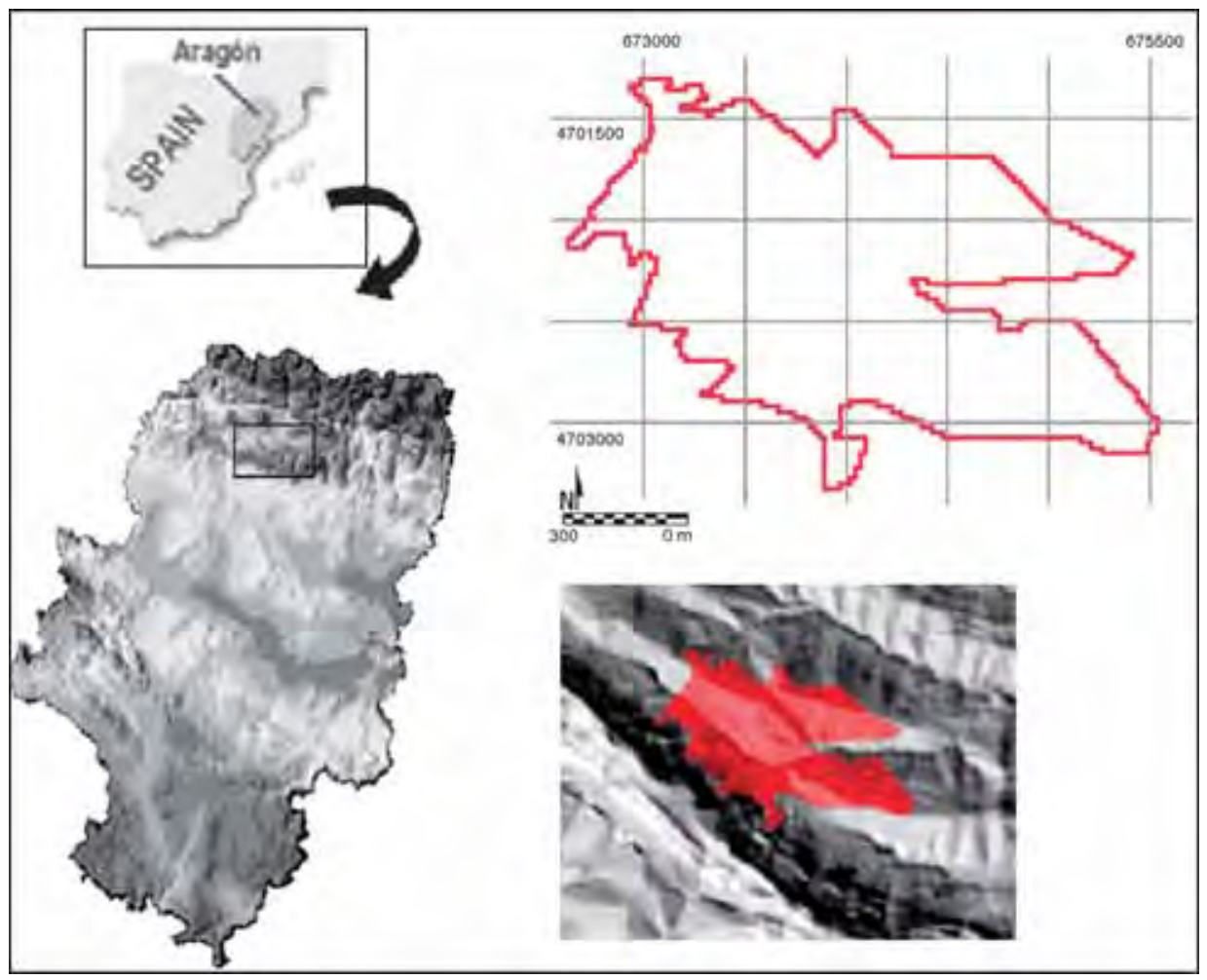

Figura 1. Localización del área de estudio

Las formaciones vegetales más representativas de la zona quemada se corresponden con diferentes facies de pinar de silvestre (Pinus sylvestris) -masas puras o mez- 
cladas con carrasca, quejigo y haya (Quercus rotundifoliae, Quercus gr. cerrioides y Fagus sylvatica, respectivamente)-, formaciones correspondientes a repoblaciones forestales de escasa talla, poco integradas con el medio, y fruticedas de boj, erizón y aliaga (Buxus sempervirens, Echinospartum horridum y Genista scorpius, respectivamente).

\subsection{Selección de imágenes de satélite y pretratamientos aplicados}

El trabajo se ha basado en la utilización de 6 imágenes Landsat Thematic Mapper (centro: long. 0³6'38', lat. 42²3'4',). Dos de las imágenes se corresponden con fechas previas al fuego (1987 y 1989), una recoge la zona quemada un año después (1991) y las tres restantes permiten analizar el incendio de Nofuentes varios años después al fuego $(1993,1994,1997)$. Todas las imágenes se corresponden con el verano, toda vez que las imágenes recogidas en esta estación minimizan las sombras topográficas -típicas del otoño e invierno-, disminuyen los problemas de los rasgos geométricos de la iluminación y la variabilidad fenológica de las imágenes de primavera y otoño (Melià et al., 1997).

El trabajo se encuadra en el campo de las técnicas de detección de cambios, que en el ámbito de la teledetección se basan en las comparaciones, píxel a píxel, de los ND de diferentes imágenes. Por tanto, es imprescindible garantizar la consistencia radiométrica y geométrica de todas las imágenes con el propósito de eliminar cualquier cambio en los ND de la escena que no sea debido a cambios reales (Elmore et al., 2000; Chuvieco, 2002). La corrección geométrica se ha realizado mediante un procedimiento de tipo no orbital utilizándose un polinomio de $2^{\circ}$ orden. Para la corrección radiométrica se ha optado por la homogeneización de las imágenes, convirtiéndolas a valores de reflectividad espectral, utilizando un procedimiento basado en los trabajos de Pons y Roure (1993) y Pons y Solé (1994).

Tras la homogeneización de la serie de imágenes se han extraído los NDVI y se han categorizado los valores en 10 intervalos regulares considerando las imágenes previas al fuego y un NDVI de 0 como valor mínimo. Posteriormente se ha delimitado el perímetro de la zona quemada siguiendo la metodología descrita en Pérez-Cabello y de la Riva (1998), y Pérez Cabello (2002). Para la realización de los pretratamientos y la extracción de los NDVI de cada imagen se ha utilizado ERDAS 8.7 como software.

\subsection{Cartografía y caracterización de las formaciones vegetales}

La identificación del tipo de formaciones vegetales afectadas se ha apoyado en la información disponible en el Mapa forestal de Aragón 1:50.000 y en la cartografía propia derivada de un proceso de clasificación digital supervisado, aplicando un algoritmo de máxima verosimilitud. Los tipos de vegetación cartografiados son: hayedos, quejigales, encinares, pinares, matorral de boj, matorral-pastizal y zonas de escasa vegetación (Figura 2). 


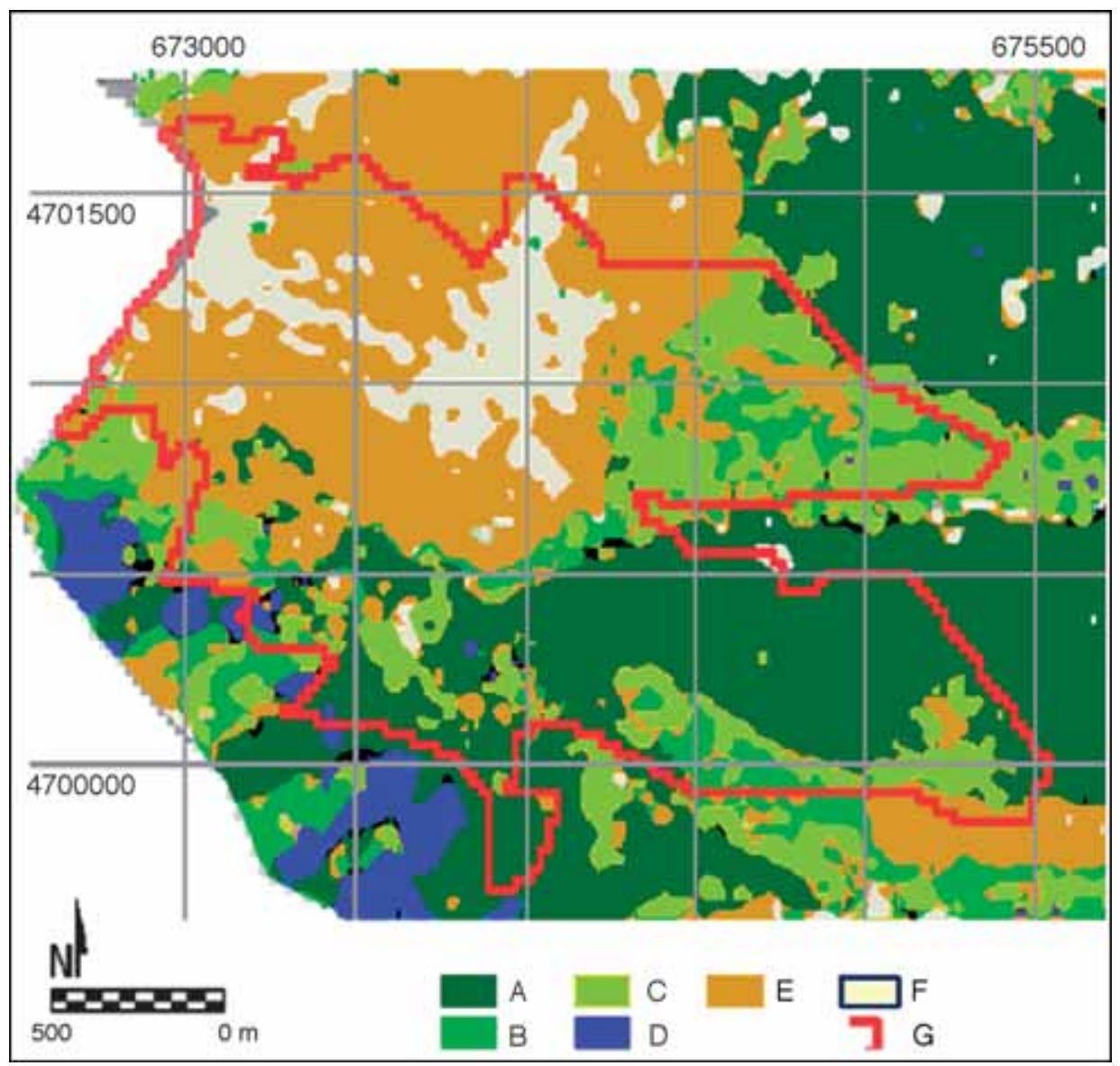

Figura 2. Distribución de los tipos de vegetación en la zona quemada (A: Pinares;

B: Encinares; C: Quejigares; D: Hayedos; E: Matorrales de Buxus sempervirens; F: Matorral-pastizal; G: Perímetro de la zona quemada)

De manera complementaria, para conocer la composición florística y las características fisionómicas de dichas formaciones, se han realizado una serie de inventarios florísticos en el campo siguiendo la metodología de Braun-Blanquet (1979), incorporando el análisis por estratos de Bertrand (1966); no obstante, se ha estimado el porcentaje de recubrimiento -en función de la proyección vertical de la parte aérea de los individuos y los estratos considerados de cada especie en relación con la superficie del inventario y con la del estrato donde se sitúa. Por tanto, los índices de abundancia/dominancia se aplican a cada uno de los estratos conformantes y a las especies vegetales integradas en cada uno de ellos, tomando como referencia las propias dimensiones del estrato donde se inscriben; en consecuencia, aunque un estrato tenga un índice de 1, las diferentes especies que lo integran pueden tener valores de 5 ó 4. 
Las características generales de los diferentes tipos de vegetación se describen a continuación. Las formaciones de quercíneas presentan un recubrimiento acumulado del $155 \%$, estando presentes los cinco estratos. Los superiores (4 y 5) presentan recubrimientos cercanos al 20\%, el arbustivo es ligeramente superior (35\%) y los inferiores se sitúan próximos al 50\%, mostrando una estructura piramidal típicamente representativa de los bosques con dinámica progresiva. Junto al pino (10’4\%), Quercus gr. cerrioides (7'5\%), Buxus sempervirens y Juniperus oxycedrus son las especies dominantes (30'1\% y 6’3\%, respectivamente). Los pinares están presididos por Pinus sylvestris y presentan un recubrimiento acumulado superior al 130\%, siendo el estrato arbóreo el más desarrollado (70\%). El resto de estratos, en especial los inferiores, apenas están presentes. Las fruticedas de boj representan estructuras arbustivas dominadas fundamentalmente por Buxus sempervirens y Genista scorpius. Las zonas de matorral/pastizal se sitúan en un sector incendiado en los años setenta y repoblado con Pinus sylvestris mediante aterrazado. En este contexto domina el estrato pascícola, sobresaliendo el boj y la aliaga.

\subsection{Extracción de los valores de diversidad}

El Índice de Shannon (H') tiene en cuenta tanto la abundancia como la proporción de las categorías presentes. La expresión matemática del índice es la siguiente:

$$
H^{\prime}=-\sum_{i=1}^{m} p_{i}^{*} \ln \left(p_{i}\right)
$$

donde pi es la fracción del área de muestreo ocupada por el NDVIi, y $m$ es el número de atributos en el área de muestreo (Shannon y Weaver, 1962). Por tanto, calcula la proporción de la categoría $i$ en relación con el número total de categorías (pi) y luego se la multiplica por el logaritmo natural de esta proporción (lnpi).

A partir de los NDVI discretizados y utilizando una kernel de 3 x 3 píxeles, se han obtenido cartografías del Índice para cada año. En atención a la sensibilidad del NDVI a las condiciones meteoro-fenológicas del momento de la captura de la imagen se han definido tres componentes representativos de los valores de diversidad. El primero

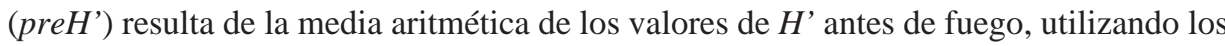
años 1987 y 1989. Para los valores posteriores se utilizan los valores absolutos de 1991 $\left({ }_{91} H^{\prime}\right)$-medición de la diversidad del paisaje a corto plazo y la media de los años 1997 , 1994 y 1993 (post H’) -medición de la diversidad a medio plazo-. También se han extraído una serie de variables que expresan los cambios de la diversidad en términos relativos; ${ }_{91}$ DifH' $^{\prime}$ representa las diferencias entre el nivel previo de diversidad ( $\mathrm{preH}^{\prime}$ ) y los valores absolutos de $1991\left({ }_{91} H^{\prime}\right)$.

Como consecuencia de la diferente extensión que ocupan las comunidades vegetales seleccionadas se ha procedido a la selección de cuatro áreas test, dispuestas sobre la superficie quemada del incendio de Nofuentes, con una extensión de $400 \mathrm{~m}$. de lado cada una (Figura 3) representativas de la diversidad existente. 


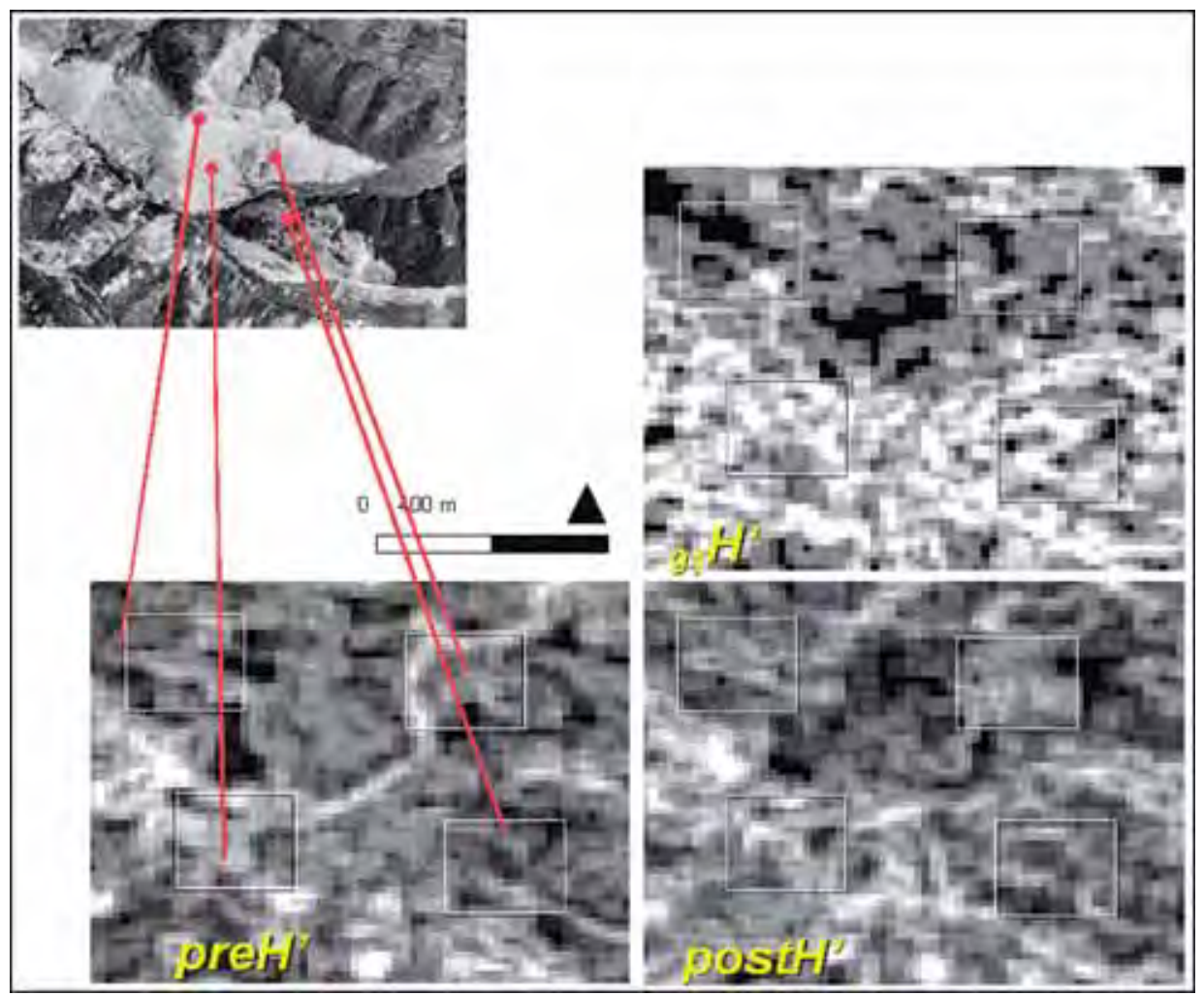

Figura 3. Distribución de los sectores analizados y cartografía de los compuestos de diversidad

Por último, mediante Anovas se construye una serie de test y gráficos para comparar los valores medios de las variables y compuestos considerados en relación con los diferentes tipos de cubierta. Mediante contrastes sobre la igualdad de medias (Multiple Range Test), se comparan las categorías del predictor, dos a dos, con el propósito de detectar diferencias estadísticamente significativas entre sí; se ha utilizado el método LSD protegido (Least Significant Differences).

\section{Resultados}

Se presentan los resultados obtenidos analizando en primer lugar las condiciones previas de heterogeneidad, a continuación la heterogeneidad un año después del incendio y, finalmente, las condiciones a medio plazo. La Figura 4 recoge los valores globales para cada tipo de vegetación considerando los compuestos de diversidad propuestos.

\subsection{Condiciones previas de heterogeneidad}

La disponibilidad de imágenes previas al impacto del fuego (1987 y 1989) permite reconocer la distribución del recubrimiento (NDVI) y de los niveles de diversidad 
en cada una de las comunidades consideradas. A este respecto, a pesar de que las imágenes se centran en el mismo mes, se han detectado diferencias estadísticamente significativas entre las distribuciones de las variables $N D V I_{87}$ y $N D V I_{89}\left(\mathrm{Z}_{\text {wilcoxon }}=-4.767\right.$, $\mathrm{p}<0,001)$ y entre las variables ${ }_{87} H^{\prime} \mathrm{y}_{89} H^{\prime}(\mathrm{T}=4.744, \mathrm{p}<0,001)$, debido a la sensibilidad del NDVI a las variaciones fenológicas de la vegetación como consecuencia de los diferentes contenidos de humedad. Para paliar esta disfunción se ha utilizado como nivel de referencia un valor medio entre las variables ${ }_{87} H^{\prime}$ y ${ }_{89} H^{\prime}$ disponible en el compuesto $p r e \_H^{\prime}$.

La correspondencia entre los valores del $\mathrm{NDVI}_{\text {PREVIO }} \mathrm{y}$ los diferentes tipos de cubierta se resuelve en los términos esperados; las cubiertas arbóreas presentan los niveles medios más elevados (próximas a la categoría 7), y los matorral con pastizal y las zonas de escasa vegetación los más bajos (en torno al nivel 5). En cualquiera de los casos se registran rangos de valores muy reducidos.

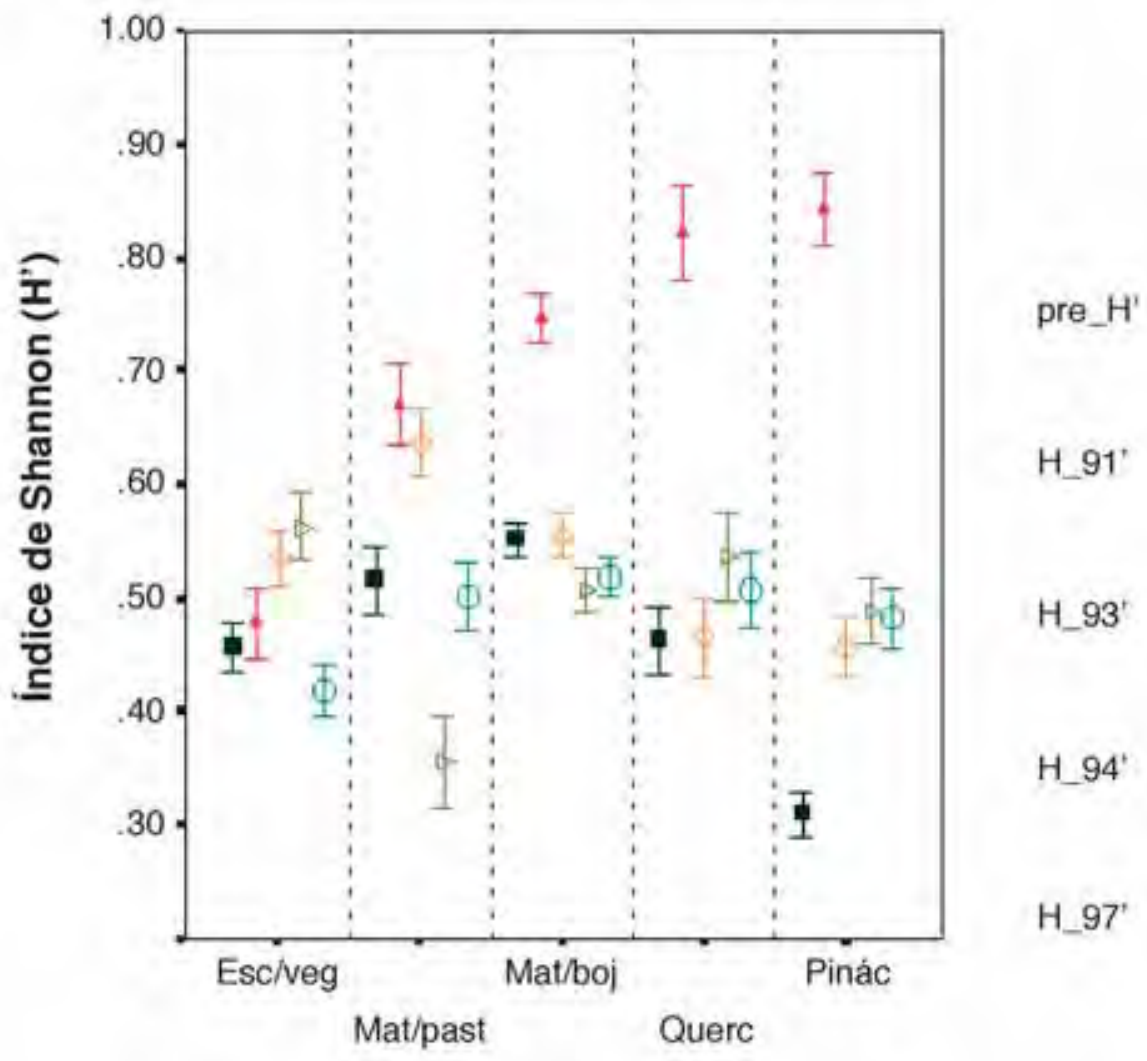

Figura 4. Resumen de la distribución de los valores de diversidad por año: rango de valores a partir de media poblacional con una probabilidad del 95\% 
Desde el punto de vista de la diversidad, los niveles más elevados se corresponden con las fruticedas dominadas por Buxus sempervirens y las formaciones de matorralpastizal ( $p r e \_H^{\prime}=0,552$ y 0,516 , respectivamente). En un nivel inferior encontramos las formaciones de quercíneas y las áreas de escasa vegetación $(0,463$ y 0,457, respectivamente), siendo los pinares la categoría que presenta los valores más bajos $(0,309)$. Este último extremo se relaciona con la mayor compacidad y continuidad de los niveles de recubrimiento que estas formaciones arbóreas presentan antes del fuego. El alto porcentaje de recubrimiento que presentan los estrados superiores en estas formaciones $(70 \%)$ justifica también, a escala de detalle, la compacidad fisionómica de estas comunidades. Mientras, en las zonas de matorral la coexistencia de zonas de suelo desnudo explica la mayor diversidad. Las pruebas de comparaciones múltiples revelan la existencia de diferencias estadísticamente significativas entre las medias de los grupos, excepto en el par integrado por las quercíneas y las zonas de escasa vegetación que presentan valores muy próximos entre sí.

\subsection{Condiciones de heterogeneidad a corto plazo}

Un año después del incendio los valores de NDVI experimentan un incremento muy acusado en la mayoría de los tipos de vegetación considerados. En lo que respecta a la diversidad, el rápido recubrimiento vegetal que se produce tras el fuego -protagonizado especialmente por una serie de herbáceas perennes, competidoras tolerantes a restricciones, capaces de maximizar la obtención de nutrientes tras el fuego-, junto a la pervivencia de restos de necromasa y de zonas de ceniza, propicia un acusado incremento de los valores de heterogeneidad espacial, siendo en todos los tipos de cubiertas netamente superiores a los computados antes de la perturbación. También se han encontrado diferencias significativas entre pares a excepción del formado por las comunidades arbóreas, donde, al mismo tiempo, se computan los mayores niveles de diversidad $(0,822$ en el caso de las quercíneas y 0,843 en las pináceas).

En términos relativos, son los pinares las comunidades forestales que experimentan un mayor valor de diversidad (compuesto $\mathrm{Dif}_{91} H^{\prime}=172 \%$ ), seguido de las comunidades dominadas por quercíneas (78\%), las arbustivas dominadas por Buxus sempervirens y el matorral-pastizal (35\% y 30\%, respectivamente) y, finalmente, las zonas con escasa vegetación (5\%), que apenas se transforman respecto al compuesto de referencia.

\subsection{Condiciones de heterogeneidad a medio plazo}

El seguimiento de la heterogeneidad a medio plazo se realiza mediante las imágenes de 1993, 1994 y 1997. En función de los datos extraídos, tres años después de la perturbación los valores de $H^{\prime}$ se aproximan a los registrados en el componente de referencia (Pre_H'), lo que representa un decremento muy acusado en relación con la diversidad un año después del fuego. Concretamente, los valores relativos de diversidad en relación con pre_H' $H^{\prime}$ suponen un incremento tan sólo del $1 \%$ en el caso de las quercíneas y de los matorrales de boj, un $23 \%$ en el matorral/pastizal y un $48 \%$ en coníferas. Por tanto, los efectos del fuego sobre la diversidad se ven neutralizados en un corto 
período de tiempo. Este fenómeno es especialmente destacable en las comunidades más resilientes, es decir, en aquellas que demandan menos recursos para su restauración, caso de los matorrales y encinares.

Otro aspecto especialmente reseñable es que se recogen valores muy similares entre las diferentes comunidades (valores de $H^{\prime}$ en torno a 0,4 ), de tal modo que tan sólo se han detectado diferencias significativas entre el par formado por las pináceas con las zonas de escasa vegetación, y el formado por las primeras con el matorral/pastizal. Así pues, si bien a nivel de comunidad el incendio ha supuesto un incremento de la diversidad interna en algunas comunidades, a escala global no se han encontrado diferencias estadísticamente significativas entre las diferentes comunidades, de donde se puede concluir que a medio plazo y a escala global el fuego provoca la homogeneización del paisaje, tal y como describen otros autores utilizando fuentes de información similar.

A escala de píxel, la capacidad predictiva de los niveles previos de heterogeneidad por comunidades ha sido evaluada mediante regresiones lineales entre pre_H' $H^{\prime}$ post_H' $H^{\prime}$. En este sentido se han encontrado correlaciones significativas en los cuatro casos ( $\mathrm{p}<0,0001)$ si bien el grado de correlación es muy bajo en todos ellos. El $\mathrm{r}^{2}$ más elevado se registra en el matorral/pastizal $\left(\mathrm{r}^{2}<0,45\right)$, a continuación los matorrales de boj $(0,31)$, las quercíneas $(0,25)$ y, finalmente, las pináceas con un $r^{2}$ de 0,10 . Los coeficientes de pendiente $(\mathrm{m})$ decrecen con el grado de estructuración fisionómica de las comunidades antes del fuego, poniendo de manifiesto la mayor resiliencia de las comunidades menos estructuradas.

\section{Conclusiones}

Un año después del fuego todos las comunidades vegetales analizadas presentan un incremento sustancial de los valores de $H^{\prime}$. Este extremo se explica por la coexistencia de los diferentes ritmos de respuesta vegetal de las comunidades afectadas, de los restos de materiales calcinados y, sobre todo, del escaso intervalo de tiempo transcurrido desde el momento del fuego. Sin embargo, este incremento es inversamente proporcional a la diversidad paisajística previa a la perturbación, de tal modo que son los pinares, los ecosistemas más homogéneos, los que incrementan más los valores de $H^{\prime}$, lo que hace mantener las diferencias entre ecosistemas y, en consecuencia, la estructura del paisaje previo.

La componente de diversidad del paisaje 3/5/7 años después muestra valores que, aun siendo superiores a los previos, son mucho más bajos que los computados en 1991, lo que se traduce en el proceso de transición a la situación previa. Sin embargo, un hecho muy destacable es que las diferentes comunidades presentan valores muy similares entre sí, de tal modo que no se computan diferencias estadísticamente significativas entre los mismos. Es decir, tras el fuego se incrementa la diversidad interna en cada ecosistema, pero presentando valores similares entre sistemas, lo que supone que, a escala global, la diversidad de paisaje presente una mayor homogeneidad. A los tres años se alcanzan niveles de diversidad que se mantienen en el tiempo, al menos durante 4 años más. Nive- 
les, en cualquier caso, ligeramente superiores a los precedentes en pinares y encinares y semejantes en las fruticedas.

\section{Agradecimientos}

Este estudio contó con el apoyo económico del Ministerio de Ciencia y Tecnología español y del Gobierno de Aragón, a través de los proyectos RS-FIRE (CGL200504863) y PIR-FIRE (PIP098/2005), respectivamente.

\section{Referencias bibliográficas}

Bertrand, G. (1966). Pour une étude géographique de la végétation. Revue Géographique des Pyrénées et du Sud-Ouest 37: 129-145.

Braun Blanquet, J. (1979). Fitosociología. Bases para el estudio de las comunidades vegetales. Blume, Madrid, $820 \mathrm{pp}$.

Burrough, P.A. y McDonell, R.A. (1998). Principles of Geographical Information Systems. Oxford University Press, Oxford.

CAIN, D.H., RitTers, K. y ORVIS, K. (1997). A multi-scale analysis of landscape statistics. Landscape Ecology (12) 4: 199-21.

Chuvieco, E. (1996). Empleo de imágenes de satélite para medir la estructura del paisaje: análisis cuantitativo y representación cartográfica. Serie Geográfica 6: 131-147.

Chuvieco, E. (1999). Measuring changes in landscape pattern form Satellite images: short-term effects of FIRE on spatial diversity. International Journal of Remote Sensing 20 (12): 2331-2346.

Chuvieco, E. (2002). Teledetección ambiental. La observación de la Tierra desde el Espacio. Ariel Ciencia, Editorial Ariel, Barcelona.

Díaz Delgado, R. y Pons, X. (1999). Seguimiento de la regeneración vegetal postincendio mediante empleo de NDVI. Revista de teledetección 12: 73-78.

Díaz Delgado, R. y Pons, X. (2001). Spatial patterns of forest fires in Catalonia (NE of Spain) along the period 1975-1995. Analysis of vegetation recovery after fire. Forest Ecology and Management 147: 67-74.

Díaz Delgado, R., Salvador, R. y Pons, X. (1998). Monitoring of plant community regeneration after fire by remote sensing. En Fire Management and Landscape Ecology (Trabaud, L. Ed.), Centre d'Ecologie Fonctionnelle et Evolutive (CNRS), Montpellier, 315-326.

ELmore, A., Mustard, J., Manning, S. y Lobell, D. (2000). Quantifying Vegetation Change in Semiarid Environments: Precision and Accuracy of Spectral Mixture 
Analysis and the Normalized Difference Vegetation Index. Remote Sensing of Environment 73: 87-102.

FERRÁn, A. y VAllejo, R. (1998). Long-term plant regeneration after wildfires in Mediterranean ecosystems of NE Spain. En Fire Management and Landscape Ecology (Trabaud, L. Ed.), Centre d'Ecologie Fonctionnelle et Evolutive (CNRS), Montpellier, 155-167.

Gamon, J.A., Field, C.B., Goulden, M.L., Griffin, K.L., Hartley, A.E., Joel, G., Peñuelas, J. y VAlentín, R. (1995). Relationships between NDVI, canopy, structure and photosynthesis in three Californian vegetation types. Ecological Applications 5: 28-41.

Gilabert, M.A., González-Piqueras, J. y García-Haro, J. (1997). Acerca de los índices de vegetación. Revista de Teledetección 8: 35-46.

Guisan, A. y Zimmermann, N.E. (2000). Predictive habitat distribution models in ecology. Ecological Modelling 135 (2-3): 147-186.

Legendre, P. y Legendre, L. (1998). Numerical Ecology. Elsevier, Amsterdam.

Lloret, F., Calvo, E., Pons, X. y Díaz-Delgado, R. (2002). Wildfires and landscape patterns in the Eastern Iberian Peninsula. Landscape Ecology 17: 754-759.

Martínez, B., Gilabert, M.A., Del Barrio, G. y Meliá, J. (2001). Desarrollo de una metodología de detección de cambios en zonas susceptible de procesos de degradación. En Teledetección. Medio Ambiente y Cambio Global (Rosell, J. y Martínez-Casanovas, J. Eds.), Universitat de Lleida y Editorial Milenio, Lleida, 110-113.

MaZerolle, M.J. y Villard, M.A. (1999). Patch characteristics and landscape context as predictors of species presence and abundance: A review. Ecoscience 6 (1): 117-124.

Melià, J., Segarra, D., Belda, F., Caballer, P., Fortea, J.C., García-Haro, J., López-Baeza, E., Moreno, J., Serrano, C. y Viedma, O. (1997). Evaluación mediante teledetección de los procesos de reforestación en zonas afectadas por incendios. En La restauración de la cubierta vegetal en la comunidad valenciana (Vallejo, R. Ed.), CEAM, Consellería de Agricultura y Medio Ambiente Generalitat Valenciana, Valencia, 149-212.

Miller, J.D. y Yool, S.R. (2002). Mapping forest post-fire canopy consumption in several overstory types using multi-temporal Landsat TM and ETM data. Remote Sensing of Environment 82: 481-496.

PAPIÓ, C. (1994). Ecologia del foc i regeneració en garrigues i pinedes mediterrànies. Institut d'estudis catalans. Barcelona, $292 \mathrm{pp}$.

Pérez-Cabello, F. (2002). Paisajes forestales y fuego en el Prepirineo occidental oscense. Un modelo regional de reconstrucción ambiental. Publicaciones del Consejo de Protección de la Naturaleza de Aragón, Serie Investigación 33, Zaragoza, $365 \mathrm{pp}$. 
Pérez-Cabello, F. y De la Riva, J. (1998). El empleo de imágenes Landsat TM para la detección y cartografía de áreas incendiadas en el Prepirineo occidental oscense. Geographicalia 36: 131-145.

Pons, X. y Roure, J.M. (1993). Caracterización espectral de siete formaciones vegetales mediterráneas a lo largo del año. En IV Reunión científica de la Asociación Española de Teledetección. Teledetección y Medio Ambiente, Sevilla, 60-69.

Pons, X. y SolÉ, L. (1994). A simple radiometric correction model to improve automatic mapping of vegetation from multispectral satellite data. Remote Sensing of Environment 48: 191-204.

Riaño, D., Chuvieco, E., Ustin, S., Zomer, R., Dennisooon, P., Roberts, D. y Salas, J. (2002). Assessment of vegetation regeneration afler fire through mulititemporal analysis of AVIRIS images in the Santa Monica Mountains. Remote Sensing of Environment 79: 60-71.

Ritters, K.H., O’Neill, R.V., Hunsaker, C.T., Wickham, J.D., Yankee, D.H., Timmis, S.P., JONES, K.B. y JACKSON, B.L. (1995). A factor analysis of landscape pattern and structure metrics. Landscape Ecology 10 (1): 23-35.

RodríGuEZ, D.A. (1996). Incendios forestales. Mundi-Prensa, Méjico.

Rouse, J.W., HaAs, R.H., Schell, J.A., Deering, D.W. y Harlan, J.C. (1974). Monitoring the vernal advancement of retrogradation of natural vegetation. NASA/GSFC. Type III. Final Report, Greenbelt MD, 371 pp.

Salvador, R. (1999). A Parametric Model for Estimating Relations Between Unprecisely Locates Field Measurements and Remotely Sensed Data. Remote Sensing of Environment 67: 99-107.

SHANnOn, C.E. y WeAVER, W. (1962). The mathematical theory of communication. University of Illinois Press, Urbana.

TRABAUD, L. (1998). Recuperación y regeneración de ecosistemas mediterráneos incendiados. Serie Geográfica 7: 37-47.

Turner, M.G. y Gardner, R.H. (1991). Quantitative Methods in Landscape Ecology. Springer-Verlag, New York.

Viedma, O., Meliá, J., Segarra, D. y García-Haro, J. (1997). Modelling rates of ecosystem recovery after fires by using Landsat TM data. Remote Sensing of Environment 61: 383-398.

WickHAM, J.D. y NorTON, D.J. (1994). Mapping and analyzing landscape patterns. Landscape Ecology 9 (1): 7-23. 